OPEN ACCESS

Edited by: Elisabetta Albi,

University of Perugia, Italy

Reviewed by:

Magda Tsolaki,

Aristotle University of

Thessaloniki, Greece

Matthew Betts,

German Center for Neurodegenerative Diseases (DZNE), Germany

${ }^{*}$ Correspondence:

Ole Isacson

isacson@hms.harvard.edu

Specialty section:

This article was submitted to

Dementia,

a section of the journal

Frontiers in Neurology

Received: 17 June 2019 Accepted: 17 September 2019 Published: 09 October 2019

Citation:

Isacson O, Brekk OR and Hallett PJ (2019) Novel Results and Concepts

Emerging From Lipid Cell Biology Relevant to Degenerative Brain Aging and Disease. Front. Neurol. 10:1053. doi: 10.3389/fneur.2019.01053

\section{Novel Results and Concepts Emerging From Lipid Cell Biology Relevant to Degenerative Brain Aging and Disease}

\author{
Ole Isacson*, Oeystein R. Brekk and Penelope J. Hallett \\ McLean Hospital and Harvard Medical School, Neuroregeneration Research Institute, Belmont, MA, United States
}

While very rare familial forms of proteinopathy can cause Parkinson's disease (PD), Lewy body dementia (LBD) and age-related dementias, recent in-depth studies of lipid disturbances in the majority of the common forms of these diseases instead suggest a primary pathogenesis in lipid pathways. This review synthesizes a perspective from new data that point to an interdependence of lipids and proteinopathy. This article describes disturbed relationships in lipid homeostasis that causes neuropathology to develop over time and with age, which includes altered mechanisms of glia-neuron exchange of lipids and inflammatory signals.

Keywords: neurons, lipids, astrocytes, microglia, inflammation, $\alpha$-synuclein, apolipoprotein, Parkinson's disease

\section{LIPID CHANGES IN PARKINSON'S DISEASE AND RELATED NEURODEGENERATION}

The relationship between lysosomal storage disorders (LSDs) and Lewy body disorders became apparent through evidence of increased risk for developing Lewy body dementia (LBD) and Parkinson's disease (PD) in carriers of LSD gene mutations, and through glycosphingolipid dysregulation and lysosomal dysfunction implicated in the normal pathophysiology of PD $(1,2)$ (Table 1). Homozygous mutations in the lysosomal hydrolase glucocerebrosidase, GBA1, are associated with the LSD, Gaucher disease. Haploinsufficiency of GBA1, which causes reduced activity of glucocerebrosidase (GCase), is associated clinically with a significantly increased risk of PD and LBD, and with faster rate of cognitive decline in $\alpha$-synucleinopathies, including LBD and PD $(3,4)$. Brain GCase activity is also decreased and corresponding glycosphingolipid substrate levels are elevated in the brain in PD without GBA1 mutations $(1,5-7)$ pointing to a much broader age-related decline, and to more complex mechanisms (8). Similar dysfunction of lysosomal hydrolases and disturbances in glycosphingolipid levels to those found clinically in PD are observed in normal aging of both mouse and human brain $(1,9)$.

Furthermore, PD gene expression and genetic analyses of large cohorts also point to an early involvement of biological processes upstream of accumulating alpha-synuclein $(\alpha$ Syn), including involvement of lipids and lipoproteins, oxidative stress, endosomallysosomal functioning, endoplasmic reticulum stress, and immune response activation $(8,10)$. In addition, with age, lysosomal enzyme function, chaperones and transporters present in the endoplasmic reticulum-Golgi complex, may become compromised at an early stage of pathogenesis. Critically, biochemical evidence shows that lysosomal enzyme loss of function and lipid disturbances creates PD-like pathology (see Table 1). 
TABLE 1 | Biochemical and clinical evidence for lysosomal enzyme loss of function and lipid disturbances creating Parkinson's disease-like pathology.

\begin{tabular}{|c|c|c|}
\hline $\begin{array}{l}\text { Relevant lysosomal biochemical pre- and clinical data for parkinson's disease and related } \\
\text { disorders }\end{array}$ & Protein affected & $\begin{array}{l}\text { Accumulating } \\
\text { substrate(s) }\end{array}$ \\
\hline $\begin{array}{l}\text { Increased risk for PD and LBD in patients carrying heterozygous GBA1 mutations. } \\
\text { Glucocerebrosidase activity is reduced in sporadic PD and in normal aging. GluCer and GluSph } \\
\text { increased in sporadic PD brain (1). }\end{array}$ & Glucocerebrosidase & $\begin{array}{l}\text { Glucosylceramide and } \\
\text { glucosylsphingosine }\end{array}$ \\
\hline $\begin{array}{l}\text { LIMP-2, which transports GCase to lysosome, is encoded by SCARB2. SCARB2 gene variants are } \\
\text { associated with PD and LBD risk (11, 12). LIMP-2 deficiency in mice causes GCase activity } \\
\text { reduction, glycolipid accumulation and } \alpha \text { Syn aggregates (13). }\end{array}$ & Glucocerebrosidase & Glucosylceramide \\
\hline $\begin{array}{l}\text { Granulin (GRN) gene variants associated with PD risk (14). Progranulin deficiency in mice leads to } \\
\text { reduced GCase activity (15). }\end{array}$ & Glucocerebrosidase & - \\
\hline $\begin{array}{l}\text { Clinical reports of parkinsonism in Fabry disease patients (16). Reduced activity of } \alpha \text {-galactosidase } \\
\text { A in leukocytes of PD patients (17). }\end{array}$ & $\alpha$-galactosidase A & Globotriasylceramide \\
\hline $\begin{array}{l}\text { Generalized dystonia associated with akinetic-rigid Parkinsonism reported in patients with GM1 } \\
\text { gangliosidosis (18) (caused by a } \beta \text {-galactosidase deficiency). Lactosylceramide is utilized in } \\
\text { ganglioside biosynthesis. }\end{array}$ & $\beta$-galactosidase & Lactosylceramide \\
\hline $\begin{array}{l}\text { Mutations in SMPD1 lead to Niemann-Pick disease type A or B and accumulation of sphingomyelin, } \\
\text { and are also associated with increased risk for PD (19). }\end{array}$ & Acid sphingomyelinase & Sphingomyelin \\
\hline $\begin{array}{l}\text { Phosphorylated } \alpha \text { Syn and Tau in neurons and oligodendrocytes in Niemann-Pick disease type C } \\
\text { patient brain (20). }\end{array}$ & NPC1 and 2 & Cholesterol, sphingolipids \\
\hline$\alpha$-synucleinopathy reported in the brain of patients with Krabbe's disease (21). & Galactocerebrosidase & Galactosylsphingosine \\
\hline $\begin{array}{l}\alpha \text {-synucleinopathy reported in brain of patients with Sandhoff disease, as well as in Hexb deficient } \\
\text { mice }(22,23) . \text { Parkinsonism reported in patients with Sandhoff disease }(24) .\end{array}$ & $\beta$-hexosaminidase $A$ and $B$ & GM2 ganglioside \\
\hline $\begin{array}{l}\text { Variation in NAGLU associated with risk for PD. Intracellular aSyn accumulation in cortical tissue } \\
\text { from Sanfilippo A syndrome cases (25). }\end{array}$ & $\begin{array}{l}\mathrm{N} \text {-acetylglucosaminidase, } \\
\mathrm{N} \text {-sulfoglucosamine } \\
\text { sulfohydrolase }\end{array}$ & Heparin sulfate metabolites \\
\hline
\end{tabular}

With age, many mechanisms can compromise lysosomal enzyme function, including loss of chaperones and transporters present in the endoplasmic reticulum-Golgi complex. Insufficiency of such lysosomal enzymes puts certain cells and brain regions at risk over the longer time frame associated with a relative increase of longevity in humans, creating risk for age-related neurodegenerative diseases (8).

Over the last decades there has been a large emphasis placed on the idea of "proteinopathy", conceptualized primarily in two versions. First, as a primary mechanism for cell dysfunction and degeneration in PD and other diseases with cellular protein aggregates, which however may only be true in very rare genetic cases with gene copy number variations (CNVs) or rare mutations (26). For example, whilst familial PD cases with CNVs of $\alpha$ Syn (duplication, triplication) cause genetic PD and LBD and protein elevations, such cases are very rare; there are currently $\sim 80$ individuals worldwide carrying these CNVs diagnosed with PD/LBD (26), compared to an estimated 6 million cases of PD worldwide (27). Second, the theory of causative proteinopathy has been extended to encompass extra-neural spread of toxic proteins in order to explain regional patterns of chronic cellular pathology seen in many neurodegenerative disorders. Evidence of physical $\alpha$ Syn spread between cells in human PD and related diseases remains to be established, and so far is demonstrated only in artificial experimental model systems.

Instead, more obvious causes for cell dysfunction and pathologies in PD and other related disorders, are primary disturbances from lipids and other metabolic stressors, which in turn can produce protein elevation and aggregation. Lewy body inclusions, widely believed to be predominantly composed of proteinaceous filaments, are in fact more co-labeled with lipids $(28,29)$. Importantly, recent ultrastructural findings demonstrate that Lewy bodies and neurites in PD post-mortem brain are composed of abundant membranous structures, abnormal vesicles and autophagosome-like structures, in addition to disrupted cytoskeletal elements and dysmorphic mitochondria (30). In summary, the previous almost exclusive focus on aggregating proteins in familial and sporadic cases of PD and LBD, may be replaced by a critical analysis of intracellular lipids and dysfunctional lipid transport as primary mechanisms of disease; in concert with inflammatory processes for PD and LBD. Such analyses may be very useful in the future for selecting candidates, biomarkers and modalities for treatments.

How can perturbation of glycolipid metabolism and lysosomal homeostasis in the aging brain precede or be upstream of protein handling? Glycolipids are abundant in plasma and intracellular membranes and are particularly enriched in the brain where they act as cell surface recognition molecules, as well as having essential roles in the regulation of membrane fluidity and lipid raft formation, modulation of membraneprotein function and signal transduction (31). When GCase in inhibited in vivo, there is large accumulation of high molecular weight aggregates of $\alpha$ Syn (32) and in vivo genetic models of primary GBA mutations also produce significant $\alpha$ synucleinopathy over time $(33,34)$. These $\alpha$-synucleinopathies can be reversed or prevented by agents that increase GCase, or otherwise reduce the accumulation of glycolipids $(33,35)$. 
In conclusion, the physiological burden of elevated neuronal glycolipid load in aging and in PD/LBD would affect multiple organelles and biological pathways, and may lower the threshold for developing PD and related neurodegenerative disorders, or accelerate pathophysiological processes in vulnerable neurons.

\section{NEURON-GLIA INTERACTIONS DURING LIPID DYSHOMEOSTASIS}

Abnormal glycolipid, neutral lipid and protein homeostasis within PD and LBD susceptible neurons are likely to signal to surrounding cells, including microglia and astrocytes, accelerating neurodegeneration (36, 37) (Figure 1A). Understanding how glycolipid changes can drive the inflammatory and neurodegenerative mechanisms will be crucial in enabling the development of novel therapeutics. Elevation of reactive oxygen species, mitochondrial dysfunction and loss of autophagy in neurons leads to elevated lipid particle formation (and peroxidated fatty acids). Such lipid dyshomeostasis in neurons may lead to subsequent accumulation of lipid droplets and eventually larger undigested lipid particles, in neurons, and potentially neighboring microglia (39-41) and Isacson, Brekk, Hallett unpublished observation. Appropriate lipid transfer between these cells via lipid transporters such as apolipoproteins, is essential for this process, and for maintaining metabolic integrity of the neuron (40). Peroxidated fatty acids released by neurons are bound to lipoproteins, which are endocytosed by glia (41). Disrupting the transport of lipids from neurons to glia for lipid droplet formation under conditions of neuronal stress, leads to neurodegeneration (39).

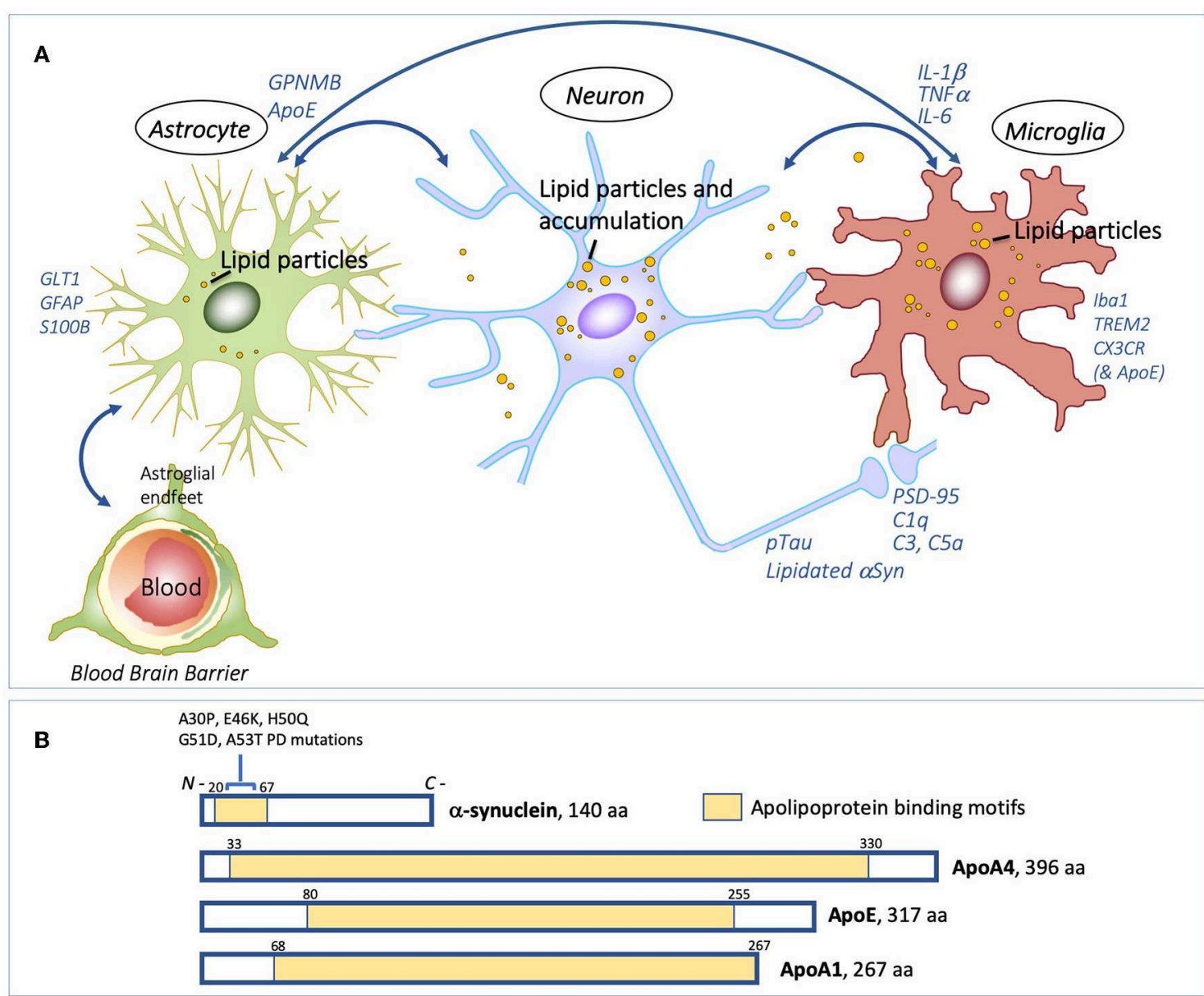

FIGURE 1 | Interdependence of lipid processing and proteinopathy. Lipids, and glia-neuron exchange of lipids and inflammatory signals (A) Proposed model for pathogenic lipid perturbations in human PD. Overall accumulation of glycolipids in the substantia nigra with differentially altered lipid droplet deposition in neurons and glial cells could facilitate aberrant protein-lipid interactions (e.g. with $\alpha$ Syn and pTau), in turn perturbing the neuron-glia lipid exchange and activating GPNMB inflammatory protein signals. Cellular dysfunction caused by elevated glycolipids could converge on downstream cytokine-signaling, and other immune responses, in neurons, microglia and astrocytes, causing excessive and aberrant neurite and synaptic damage ultimately leading to neurodegeneration. (B) $\alpha$ Syn has a role in lipid binding through its 11-amino acid repeat amphipathic helical region (shaded in yellow). Mutations in aSyn associated with familial PD, A30P, E46K, H50Q, G51D, and A53T, all occur within this region. $\alpha$ Syn shares conserved tandem repeat regions with the apolipoproteins, ApoA4, ApoE, and ApoA1 (yellow shading). Under lipid stress or aging, $\alpha$ Syn can become significantly lipidated, which may also create dysfunction leading to Lewy bodies. Schematic in (A) is original by the authors. Schematic in (B), showing apolipoprotein binding motifs, is adapted and modified from Emamzadeh (38), under terms of the Creative Commons CC BY license. 
Glycoprotein non-metastatic protein B $(G P N M B)$ is a type-I transmembrane glycoprotein that seems to be mechanistically related to altered glycolipid levels (42). In the brain, GPNMB is expressed primarily in glial cells and is thought to play a role as an inflammatory regulator to prevent chronic inflammation (43). Polymorphisms in GPNMB are found to associate with idiopathic PD (44), and GPNMB protein levels are selectively increased in the substantia nigra of PD patients (42). In Gaucher disease, increased protein levels of GPNMB correlate with disease severity and progression $(45,46)$. Upon systemic pharmacological induction of lipidopathy in mice, which also causes $\alpha$-synucleinopathy, GPNMB is elevated in a brain-region specific manner including the hippocampus, substantia nigra and cerebral cortex (42). This regional specific upregulation of GPNMB may reflect a differential response of brain regions to lysosomal dysfunction and subsequent differential vulnerability of neuronal populations to degeneration $(42,47)$. In this lipidopathy model, GPNMB elevation is also associated with robust glial activation and GPNMB is localized in astrocytes and microglia (42). Of note, GPNMB is not elevated by increased $\alpha$ Syn alone in transgenic mice overexpressing human $\alpha$ Syn, indicating a selective response to lipid perturbations (42).

\section{$\alpha$ SYN AS A LIPID-CARRYING PROTEIN}

aSyn is abundant in neurons and is highly enriched at presynaptic terminals, and it is also associated with some organelles. $\alpha$ Syn has important functional roles in the regulation of vesicles, such as synaptic vesicles, neurotransmitter release, dopamine metabolism, synaptic activity, and plasticity (48). $\alpha$ Syn can interact with various lipid species through its amphipathic N-terminus (amino acid) domain. The N-terminal region of $\alpha$ Syn contains six hexameric repeats of 11 amino acids which are characteristic of the 11 amino acid repeats that mediate lipid interactions of apolipoproteins $(38,49)$ (Figure 1B). Significantly, all mutations in $\alpha$ Syn which are associated with familial PD, are located in this lipid-binding region. In the brain, apolipoprotein $\mathrm{E}$ (apoE) is the most abundant lipoprotein, forming lipoprotein particles and binding to ApoE cell surface receptors for the delivery of cholesterol and other lipids to neurons. The APOE4 isoform allele is associated with increased risk for dementias in Lewy body diseases, including LBD and PD (50). Interestingly, plasma protein levels of another apolipoprotein, apolipoprotein A1, are associated with age of onset and motor severity in early PD (51). $\alpha$ Syn has several apolipoprotein-like characteristics, including regulation of cholesterol efflux in neuronal cells and formation of lipoprotein nanoparticles $(52,53)$ providing a clear premise for $\alpha$ Syn's function as a lipid-carrying molecule. Statin treatment in a rodent $\alpha$-synucleinopathy model reduces $\alpha$-synuclein aggregates and neuronal pathology (54). The role of $\alpha$ Syn as a functional apolipoprotein is also highlighted by the finding that there is a worsening of ApoE4-mediated pathology in mice that carry human apoE4 when mouse $\alpha$ Syn is ablated (55). Levels of neutral lipids are elevated in the brain in mice that lack endogenous $\alpha$ Syn (56). In perspective, given these data it appears that $\alpha$ Syn normally is not participating in lipid transport in roles that involve synaptic transmission and vesicular functions at the synapse, but can become lipidated under cellular stressful conditions that involve glycolipid, sphingolipid, neutral lipid, lipid peroxidation and age-related disturbances (7). In such circumstances, $\alpha$ Syn becomes part of a pathological adaptation to resolve the lipid problems (55), which likely leads to vesicular binding and transport changes that precede Lewy body formation.

Apolipoprotein function is also linked with inflammation, and ApoE is a modulator of immune responses (57) (Figure 1A). Mice lacking ApoE show similar immune activation to mice expressing human ApoE4 in response to lipopolysaccharide (58), and expression of complement pathway genes are upregulated in ApoE knockout mice (59). ApoE has also recently been shown to form a complex with $\mathrm{C} 1 \mathrm{q}$ within lipid compartments where it is a regulator of the classical complement cascade (59). C1q is implicated as an early mediator of neuronal dysfunction in preclinical models of $\mathrm{AD}$, whereby reduced expression or blockade of $\mathrm{C} 1 \mathrm{q}$ rescues synaptic loss and dysfunction upon exposure to toxic amyloid-beta (60); similarly, C1qa knockdown mitigates neurotoxicity in an in vivo model of frontotemporal dementia (61). Furthermore, C1qa deficiency delays functional cognitive decline associated with normal aging in mice (62). Activation of the complement system is induced in lysosomal storage disorders, including models of neuronopathic Gaucher disease by inhibiting GCase (using CBE), where protein expression of $\mathrm{C} 1 \mathrm{q}$ is robustly elevated in several brain regions (32). Inhibition of the complement pathway, through genetic deficiency of C5R1a completely prevents glycolipid accumulation and inflammation in the brain following similar paradigms of systemic CBE (63).

\section{SUMMARY AND FUTURE PERSPECTIVE}

In summary, much evidence points to disruption of lipid cell biology; as glycosphingolipids, gangliosides and possibly several other lipids with metabolic influence can be early initiating factors for age-related neurodegenerative disorders such as PD and LBD (Table 1 and Figure 2). Lipid disturbances in cell types of the brain and/or in specific compartments of such cells, including neurons, astrocytes, microglia and oligodendrocytes, are involved in a large number of neurological diseases. In particular, it is now clear that PD can be triggered by lipid disturbances that are caused by lysosomal genetic or similar age-induced enzymatic loss of function. Relevant to such lipid changes, we find that lipid transport may be compromised by pathological accommodation of $\alpha$ Syn to lipid binding and altered transport roles which are not optimal for normal neuronal function (Figure 1). In particular, it is important in future research to identify lipid binding and abnormal lipid droplet or other cellular lipid formations under specific cell 


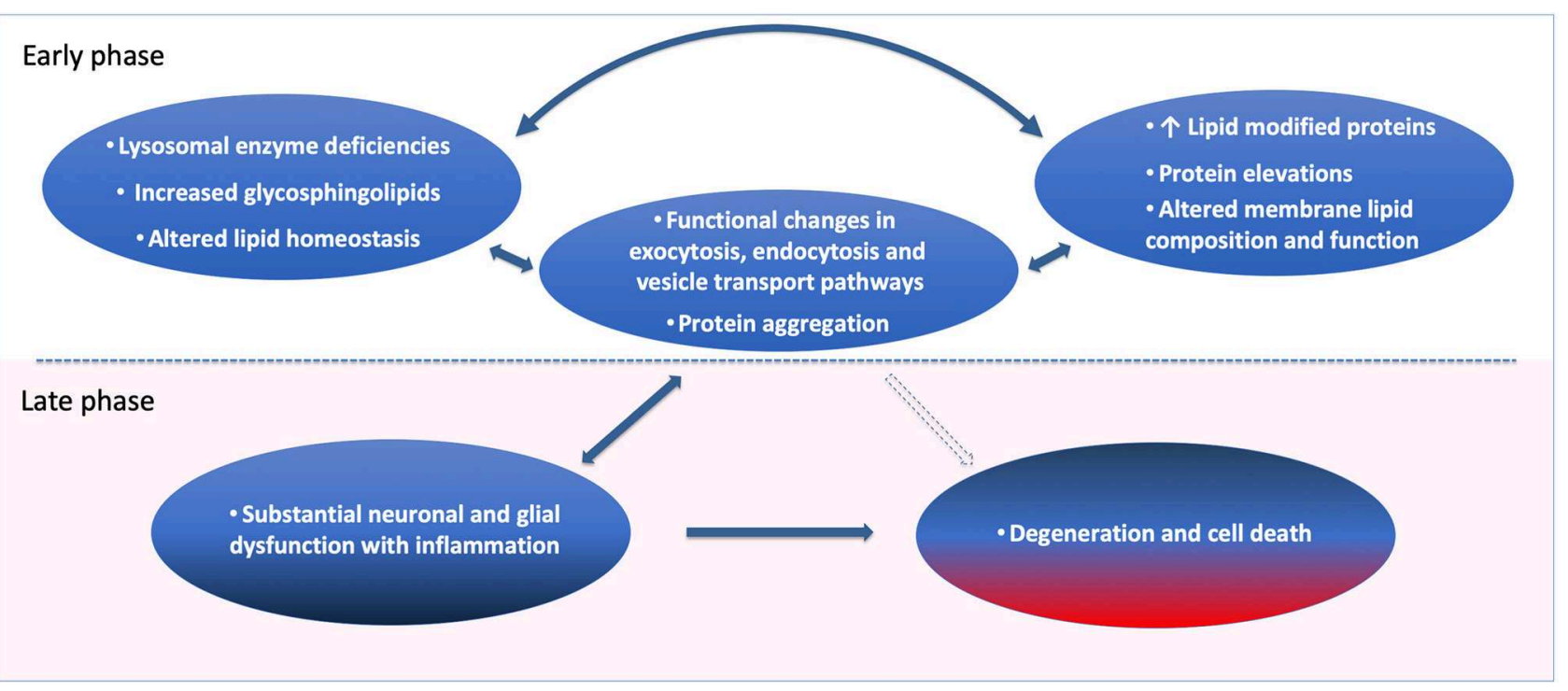

FIGURE 2 | Cell biological pathogenic factors and adaptations leading to neuronal dysfunction, synaptic degeneration, and cell death over time. Loss of lipid homeostasis and lysosomal enzyme deficiencies are the strong genetic and phenotypic drivers of age and Parkinson's disease. Sphingolipid elevations and changes in lipid metabolism can be (Early, see figure) primary pathogenic contributors, leading to protein elevations, lipid modified proteins and sphingolipid-induced membrane composition and loss of function. In the case of CNVs and in mutations of key proteins such as $\alpha$ Syn, the primary event in those extremely rare forms of PD can start with protein elevations followed by altered lipid-modified proteins, and functional changes in exocytosis, endocytosis and vesicle transport, leading to neuronal dysfunction and protein aggregation. It is reasonable to believe that these cellular changes can occur for a long time in an adaptive feedback cycle to keep the cells and neurons functional, as a form of pathological accommodation. Over time with the ongoing disease process (Late, see figure), the cell dysfunction will become severe if no external intervention is obtained, causing substantial neuronal glial dysfunction and inflammation as a result. Such conditions will lead to regional and cell type specific destruction and cell death in the brain tissue.

biological conditions. Lipid storage diseases with excessive lipid handling demand can lead to astrocytic and microglial disturbances. There are several contexts in which such lipid and associated lipid-protein interactions could eventually become pathological. The fact that the lipid-carrying APOE4 variant is associated with increased risk for $\mathrm{AD}$ and dementias may be the most explicit biological situation where apolipoprotein functions are a major driver of brain dementias. Under some conditions, $\alpha$ Syn may even have a cooperative role with apolipoproteins and lipid transport. In addition, basic research demonstrates that several proteins including $\alpha$ Syn (Figure 1B) can accommodate pathological lipid disturbances in astrocytic, neuronal and microglial compartments. In such situations, for a time affected cells will handle genetic and age-acquired lipid and metabolic disturbances, and clearly, such cells may even return to a healthier condition when the pathological stimuli are removed, or a treatment is devised that addresses the cause or initiating factor. Regardless, in chronic neurodegenerative diseases when neurons and glia are unable to maintain such cellular component functions, the pathogenic mechanisms will lead to cellular functional failures that are irreversible (see Figure 2). Inflammatory responses can be present at any of these pathogenic steps but are potentially most damaging in the later stages of degeneration, as such processes can remove cellular structures, including synapses, permanently at a structural level (Figure 2). The continuous expression of elevated amounts or aberrant lipids inside and outside neurons and glia can activate the immune system. In our opinion, novel research needs to focus on the interactions between neurons and glia as an interdependent system that attempts to regulate lipid and protein changes. When such lipid disturbances are significant they can lead to inflammatory reactions and eventually synaptic pathobiology (Figure 1A).

Lipid dyshomeostasis, transport and clearance are emerging as central causative factors in neurodegenerative diseases and should help in selecting molecular targets for medical treatments, as well as diagnostic insights to both corrective and antiinflammatory action to prevent structural degeneration in the brain. This new perspective of pathogenesis relevant, upstream causative mechanisms in several neurodegenerative diseases in PD, LBD and potentially also age-related dementias, provides optimism in developing new therapies for these devastating diseases.

The implication for the new understanding presented here; that lipid and inflammatory mechanisms can precede proteinopathies (Figure 2), provides clinical opportunities for identification of relevant and specific lipid and inflammatory biomarkers. It is already possible to measure specific abnormalities from GCase in the blood and brain $(1,64)$ of 
patients with PD. Such patient stratification in other lipid species and specific metabolic disturbances may help to better define effective treatments of neurodegenerative diseases in clinical trials. It is also important that systemic and peripheral biomarkers can be coincident with brain pathology observed in neurodegenerative diseases. There is evidence of such peripheral biomarkers in patients with LSDs, $\mathrm{PD}$, and $\mathrm{AD}$ for pathways involved in lipids and inflammation $(51,64-68)$. In conclusion, determining altered cellular lipid accumulation, transfer and clearance mechanisms in PD and related disorders can be of significant value to helping patients and at-risk individuals.

\section{REFERENCES}

1. Rocha EM, Smith GA, Park E, Cao H, Brown E, Hallett P, et al. Progressive decline of glucocerebrosidase in aging and Parkinson's disease. Ann Clin Transl Neurol. (2015) 2:433-8. doi: 10.1002/acn3.177

2. Sidransky E, Lopez G. The link between the GBA gene and parkinsonism. Lancet Neurol. (2012) 11:986-98. doi: 10.1016/S1474-4422(12) 70190-4

3. Sidransky E, Nalls MA, Aasly JO, Aharon-Peretz J, Annesi G, Barbosa ER, et al. Multicenter analysis of glucocerebrosidase mutations in Parkinson's disease. N Engl J Med. (2009) 361:1651-61. doi: 10.1056/NEJMoa09 01281

4. Mata IF, Samii A, Schneer SH, Roberts JW, Griffith A, Leis BC, et al. Glucocerebrosidase gene mutations: a risk factor for Lewy body disorders. Arch Neurol. (2008) 65:379-82. doi: 10.1001/archneurol. 2007.68

5. Huebecker M, Moloney EB, van der Spoel AC, Priestman DA, Isacson O, Hallett PJ, et al. Reduced sphingolipid hydrolase activities, substrate accumulation and ganglioside decline in Parkinson's disease. Mol Neurodegener. (2019).

6. Murphy KE, Gysbers AM, Abbott SK, Tayebi N, Kim WS, Sidransky E, et al. Reduced glucocerebrosidase is associated with increased alphasynuclein in sporadic Parkinson's disease. Brain. (2014) 137(Pt 3):834-48. doi: 10.1093/brain/awt367

7. Brekk OR, Moskites A, Isacson O, Hallett PJ. Lipid-dependent deposition of alpha-synuclein and Tau on neuronal Secretogranin IIpositive vesicular membranes with age. Nat Sci Rep. (2018) 8:15207. doi: 10.1038/s41598-018-33474-z

8. Hallett PJ, Engelender S, Isacson O. Lipid and immune abnormalities causing age-dependent neurodegeneration and Parkinson's disease. J Neuroinflammation. (2019) 16:153. doi: 10.1186/s12974-0191532-2

9. Hallett PJ, Huebecker M, Brekk OR, Moloney EB, Rocha EM, Priestman DA, et al. Glycosphingolipid levels and glucocerebrosidase activity are altered in normal aging of the mouse brain. Neurobiol Aging. (2018) 67:189-200. doi: 10.1016/j.neurobiolaging.2018.02.028

10. Klemann C, Martens GJM, Sharma M, Martens MB, Isacson O, Gasser T, et al. Integrated molecular landscape of Parkinson's disease. NPJ Parkinsons Dis. (2017) 3:14. doi: 10.1038/s41531-017-0015-3

11. Do CB, Tung JY, Dorfman E, Kiefer AK, Drabant EM, Francke U, et al. Web-based genome-wide association study identifies two novel loci and a substantial genetic component for Parkinson's disease. PLoS Genet. (2011) 7:e1002141. doi: 10.1371/journal.pgen.1002141

12. Bras J, Guerreiro R, Darwent L, Parkkinen L, Ansorge O, Escott-Price V, et al. Genetic analysis implicates APOE, SNCA and suggests lysosomal dysfunction in the etiology of dementia with Lewy bodies. Hum Mol Genet. (2014) 23:6139-46. doi: 10.1093/hmg/ddu334

13. Rothaug M, Zunke F, Mazzulli JR, Schweizer M, Altmeppen H, LullmannRauch R, et al. LIMP-2 expression is critical for beta-glucocerebrosidase activity and alpha-synuclein clearance. Proc Natl Acad Sci USA. (2014) 111:15573-8. doi: 10.1073/pnas.1405700111

\section{AUTHOR CONTRIBUTIONS}

OI drafted the article with $\mathrm{PH}$. OB contributed to the discussion and analysis of the results mentioned in the article.

\section{FUNDING}

This research was supported by NIH/NINDS 1R01NS092667, NIH/NIA R01AG060195, the Consolidated Anti Aging Foundation, and the Orchard Foundation. OB was supported by the Harold and Ronna Cooper Post Doctoral Fellowship for Parkinson's Disease Research.

14. Chen Y, Li S, Su L, Sheng J, Lv W, Chen G, et al. Association of progranulin polymorphism rs5848 with neurodegenerative diseases: a meta-analysis. J Neurol. (2015) 262:814-22. doi: 10.1007/s00415-0147630-2

15. Zhou X, Paushter DH, Pagan MD, Kim D, Nunez Santos M, Lieberman RL, et al. Progranulin deficiency leads to reduced glucocerebrosidase activity. PLoS ONE. (2019) 14:e0212382. doi: 10.1371/journal.pone. 0212382

16. Buechner S, De Cristofaro MT, Ramat S, Borsini W. Parkinsonism and Anderson Fabry's disease: a case report. Mov Disord. (2006) 21:103-7. doi: $10.1002 / \mathrm{mds} .20675$

17. Wu G, Yan B, Wang $\mathrm{X}$, Feng $\mathrm{X}$, Zhang $\mathrm{A}, \mathrm{Xu} \mathrm{X}$, et al. Decreased activities of lysosomal acid alpha-D-galactosidase $\mathrm{A}$ in the leukocytes of sporadic Parkinson's disease. J Neurol Sci. (2008) 271:168-73. doi: 10.1016/j.jns.2008.04.011

18. Roze E, Paschke E, Lopez N, Eck T, Yoshida K, Maurel-Ollivier A, et al. Dystonia and parkinsonism in GM1 type 3 gangliosidosis. Mov Disord. (2005) 20:1366-9. doi: 10.1002/mds.20593

19. Gan-Or Z, Ozelius LJ, Bar-Shira A, Saunders-Pullman R, Mirelman A, Kornreich R, et al. The p.L302P mutation in the lysosomal enzyme gene SMPD1 is a risk factor for Parkinson disease. Neurology. (2013) 80:1606-10. doi: 10.1212/WNL.0b013e31828f180e

20. Saito Y, Suzuki K, Hulette CM, Murayama S. Aberrant phosphorylation of alpha-synuclein in human Niemann-Pick type C1 disease. J Neuropathol Exp Neurol. (2004) 63:323-8. doi: 10.1093/jnen/63.4.323

21. Smith BR, Santos MB, Marshall MS, Cantuti-Castelvetri L, Lopez-Rosas A, Li $\mathrm{G}$, et al. Neuronal inclusions of alpha-synuclein contribute to the pathogenesis of Krabbe disease. J Pathol. (2014) 232:509-21. doi: 10.1002/path.4328

22. Suzuki K, Iseki E, Togo T, Yamaguchi A, Katsuse O, Katsuyama $\mathrm{K}$, et al. Neuronal and glial accumulation of alpha- and betasynucleins in human lipidoses. Acta Neuropathol. (2007) 114:481-9. doi: 10.1007/s00401-007-0264-z

23. Cachon-Gonzalez MB, Wang SZ, Ziegler R, Cheng SH, Cox TM. Reversibility of neuropathology in Tay-Sachs-related diseases. Hum Mol Genet. (2014) 23:730-48. doi: 10.1093/hmg/ddt459

24. Inzelberg R, Korczyn AD. Parkinsonism in adult-onset GM2 gangliosidosis. Mov Disord. (1994) 9:375-7. doi: 10.1002/mds.870090325

25. Winder-Rhodes SE, Garcia-Reitbock P, Ban M, Evans JR, Jacques TS, Kemppinen A, et al. Genetic and pathological links between Parkinson's disease and the lysosomal disorder Sanfilippo syndrome. Mov Disord. (2012) 27:312-5. doi: 10.1002/mds.24029

26. Book A, Guella I, Candido T, Brice A, Hattori N, Jeon B, et al. A MetaAnalysis of alpha-Synuclein Multiplication in Familial Parkinsonism. Front Neurol. (2018) 9:1021. doi: 10.3389/fneur.2018.01021

27. Dorsey ER, Sherer T, Okun MS, Bloem BR. The emerging evidence of the Parkinson Pandemic. J Parkinsons Dis. (2018) 8:S3-8. doi: 10.3233/JPD-181474

28. Araki K, Yagi N, Ikemoto Y, Yagi H, Choong CJ, Hayakawa H, et al. Synchrotron FTIR micro-spectroscopy for structural analysis of Lewy bodies in the brain of Parkinson's disease patients. Sci Rep. (2015) 5:17625. doi: $10.1038 /$ srep 17625 
29. Gai WP, Yuan HX, Li XQ, Power JT, Blumbergs PC, Jensen PH. In situ and in vitro study of colocalization and segregation of alpha-synuclein, ubiquitin, and lipids in Lewy bodies. Exp Neurol. (2000) 166:324-33. doi: 10.1006/exnr.2000.7527

30. Shahmoradian SH, Lewis AJ, Genoud C, Hench J, Moors TE, Navarro PP, et al. Lewy pathology in Parkinson's disease consists of crowded organelles and lipid membranes. Nat Neurosci. (2019) 22:1099-109. doi: 10.1038/s41593-019-0423-2

31. Xu YH, Barnes S, Sun Y, Grabowski GA. Multi-system disorders of glycosphingolipid and ganglioside metabolism. J Lipid Res. (2010) 51:1643-75. doi: 10.1194/jlr.R003996

32. Rocha EM, Smith GA, Park E, Cao H, Graham AR, Brown E, et al. Sustained systemic glucocerebrosidase inhibition induces brain alpha-synuclein aggregation, microglia and complement C1q activation in mice. Antioxid Redox Signal. (2015) 23:550-64. doi: 10.1089/ars.2015. 6307

33. Sardi SP, Clarke J, Kinnecom C, Tamsett TJ, Li L, Stanek LM, et al. CNS expression of glucocerebrosidase corrects alpha-synuclein pathology and memory in a mouse model of Gaucher-related synucleinopathy. Proc Natl Acad Sci USA. (2011) 108:12101-6. doi: 10.1073/pnas.11081 97108

34. Xu YH, Sun Y, Ran H, Quinn B, Witte D, Grabowski GA. Accumulation and distribution of alpha-synuclein and ubiquitin in the CNS of Gaucher disease mouse models. Mol Genet Metab. (2011) 102:436-47. doi: 10.1016/j.ymgme.2010.12.014

35. Sardi SP, Viel C, Clarke J, Treleaven CM, Richards AM, Park H, et al. Glucosylceramide synthase inhibition alleviates aberrations in synucleinopathy models. Proc Natl Acad Sci USA. (2017) 114:2699-704. doi: 10.1073/pnas.1616152114

36. Chung CY, Koprich JB, Siddiqi H, Isacson O. Dynamic changes in presynaptic and axonal transport proteins combined with striatal neuroinflammation precede dopaminergic neuronal loss in a rat model of AAV alpha-synucleinopathy. J Neurosci. (2009) 29:3365-73. doi: 10.1523/JNEUROSCI.5427-08.2009

37. Deleidi $M$, Isacson $O$. Viral and inflammatory triggers of neurodegenerative diseases. Sci Transl Med. (2012) 4:121ps123. doi: 10.1126/scitranslmed.3003492

38. Emamzadeh FN. Role of apolipoproteins and alpha-Synuclein in Parkinson's Disease. J Mol Neurosci. (2017) 62:344-55. doi: 10.1007/s12031-017-0942-9

39. Liu L, MacKenzie KR, Putluri N, Maletic-Savati M, Bellen HJ. The glia-neuron lactate shuttle and elevated ROS promote lipid synthesis in neurons and lipid droplet accumulation in glia via APOE/D. Cell Metab. (2017) 26:719-37.e716. doi: 10.1016/j.cmet.2017.08.024

40. Liu L, Zhang K, Sandoval H, Yamamoto S, Jaiswal M, Sanz E, et al. Glial lipid droplets and ROS induced by mitochondrial defects promote neurodegeneration. Cell. (2015) 160:177-90. doi: 10.1016/j.cell.2014. 12.019

41. Ioannou MS, Jackson J, Sheu SH, Chang CL, Weigel AV, Liu H, et al. Neuron-astrocyte metabolic coupling protects against activity-induced fatty acid toxicity. Cell. (2019) 177:1522-35.e1514. doi: 10.1016/j.cell.2019. 04.001

42. Moloney EB, Moskites A, Ferrari EJ, Isacson O, Hallett PJ. The glycoprotein GPNMB is selectively elevated in the substantia nigra of Parkinson's disease patients and increases after lysosomal stress. Neurobiol Dis. (2018) 120:1-11. doi: 10.1016/j.nbd.2018.08.013

43. Neal ML, Boyle AM, Budge KM, Safadi FF, Richardson JR. The glycoprotein GPNMB attenuates astrocyte inflammatory responses through the CD44 receptor. J Neuroinflammation. (2018) 15:73. doi: 10.1186/s12974-018-1100-1

44. International Parkinson's Disease Genomics Consortium (IPDGC) and Wellcome Trust Case Control Consortium 2 (WTCCC2). A two-stage metaanalysis identifies several new loci for Parkinson's disease. PLoS Genet. (2011) 7:e1002142. doi: 10.1371/journal.pgen.1002142

45. Zigdon H, Savidor A, Levin Y, Meshcheriakova A, Schiffmann R, Futerman AH. Identification of a biomarker in cerebrospinal fluid for neuronopathic forms of Gaucher disease. PLoS ONE. (2015) 10:e0120194. doi: 10.1371/journal.pone.0120194

46. Kramer G, Wegdam W, Donker-Koopman W, Ottenhoff R, Gaspar P, Verhoek M, et al. Elevation of glycoprotein nonmetastatic melanoma protein
B in type 1 Gaucher disease patients and mouse models. FEBS Open Bio. (2016) 6:902-13. doi: 10.1002/2211-5463.12078

47. Engelender S, Isacson O. The threshold theory for Parkinson's Disease. Trends Neurosci. (2017) 40:4-14. doi: 10.1016/j.tins.2016.10.008

48. Burre J. The synaptic function of alpha-synuclein. J Parkinsons Dis. (2015) 5:699-713. doi: 10.3233/JPD-150642

49. George JM, Jin H, Woods WS, Clayton DF. Characterization of a novel protein regulated during the critical period for song learning in the zebra finch. Neuron. (1995) 15:361-72. doi: 10.1016/0896-6273(95)90040-3

50. Tsuang D, Leverenz JB, Lopez OL, Hamilton RL, Bennett DA, Schneider JA, et al. APOE epsilon4 increases risk for dementia in pure synucleinopathies. JAMA Neurol. (2013) 70:223-8. doi: 10.1001/jamaneurol. 2013.600

51. Swanson CR, Berlyand Y, Xie SX, Alcalay RN, Chahine LM, Chen-Plotkin AS. Plasma apolipoprotein A1 associates with age at onset and motor severity in early Parkinson's disease patients. Mov Disord. (2015) 30:1648-56. doi: $10.1002 / \mathrm{mds} .26290$

52. Varkey J, Mizuno N, Hegde BG, Cheng N, Steven AC, Langen R. alpha-Synuclein oligomers with broken helical conformation form lipoprotein nanoparticles. J Biol Chem. (2013) 288:17620-30. doi: 10.1074/jbc.M113.476697

53. Hsiao JT, Halliday GM, Kim WS. alpha-synuclein regulates neuronal cholesterol efflux. Molecules. (2017) 22:E1769. doi: 10.3390/molecules22101769

54. Koob AO, Ubhi K, Paulsson JF, Kelly J, Rockenstein E, Mante M, et al. Lovastatin ameliorates alpha-synuclein accumulation and oxidation in transgenic mouse models of alpha-synucleinopathies. Exp Neurol. (2010) 221:267-74. doi: 10.1016/j.expneurol.2009.11.015

55. Bar R, Boehm-Cagan A, Luz I, Kleper-Wall Y, Michaelson D. The effects of apolipoprotein E genotype, a-synuclein deficiency, and sex on brain synaptic and Alzheimer's disease-related pathology. Alzheimer's Dement. (2018) 10:111. doi: 10.1016/j.dadm.2017.08.003

56. Barcelo-Coblijn G, Golovko MY, Weinhofer I, Berger J, Murphy EJ. Brain neutral lipids mass is increased in alpha-synuclein gene-ablated mice. J Neurochem. (2007) 101:132-41. doi: 10.1111/j.1471-4159.2006. 04348.x

57. Shi Y, Holtzman DM. Interplay between innate immunity and Alzheimer disease: APOE and TREM2 in the spotlight. Nat Rev Immunol. (2018) 18:75972. doi: 10.1038/s41577-018-0051-1

58. Zhu Y, Nwabuisi-Heath E, Dumanis SB, Tai LM, Yu C, Rebeck GW, et al. APOE genotype alters glial activation and loss of synaptic markers in mice. Glia. (2012) 60:559-69. doi: 10.1002/glia.22289

59. Yin C, Ackermann S, Ma Z, Mohanta SK, Zhang C, Li Y, et al. ApoE attenuates unresolvable inflammation by complex formation with activated C1q. Nat Med. (2019) 25:496-506. doi: 10.1038/s41591-018-0336-8

60. Hong S, Beja-Glasser VF, Nfonoyim BM, Frouin A, Li S, Ramakrishnan $S$, et al. Complement and microglia mediate early synapse loss in Alzheimer mouse models. Science. (2016) 352:712-6. doi: 10.1126/science.aa $\mathrm{d} 8373$

61. Lui H, Zhang J, Makinson SR, Cahill MK, Kelley KW, Huang HY, et al. Progranulin deficiency promotes circuit-specific synaptic pruning by microglia via complement activation. Cell. (2016) 165:921-35. doi: 10.1016/j.cell.2016.04.001

62. Stephan AH, Madison DV, Mateos JM, Fraser DA, Lovelett EA, Coutellier $\mathrm{L}$, et al. A dramatic increase of $\mathrm{Clq}$ protein in the CNS during normal aging. J Neurosci. (2013) 33:13460-74. doi: 10.1523/JNEUROSCI.1333-13. 2013

63. Pandey MK, Burrow TA, Rani R, Martin LJ, Witte D, Setchell KD, et al. Complement drives glucosylceramide accumulation and tissue inflammation in Gaucher disease. Nature. (2017) 543:108-12. doi: 10.1038/nature 21368

64. Alcalay RN, Levy OA, Waters CC, Fahn S, Ford B, Kuo SH, et al. Glucocerebrosidase activity in Parkinson's disease with and without GBA mutations. Brain. (2015) 138:2648-58. doi: 10.1093/brain/awv179

65. Cook DA, Kannarkat GT, Cintron AF, Butkovich LM, Fraser KB, Chang J, et al. LRRK2 levels in immune cells are increased in Parkinson's disease. NPJ Parkinsons Dis. (2017) 3:11. doi: 10.1038/s41531-0170010-8 
66. Sardi SP, Liu G, Scherzer A, Park H, Chiang M, Rotunno M, et al. Glucosylceramide blood test for GBA-associated Parkinson's disease: a potential companion for precision therapeutics. In: The 14th International Conference on Alzheimer's and Parkinson's Diseases (Lisbon) (2019).

67. van der Lienden MJC, Gaspar P, Boot R, Aerts J, van Eijk M. Glycoprotein non-metastatic protein $\mathrm{B}$ : an emerging biomarker for lysosomal dysfunction in macrophages. Int J Mol Sci. (2018) 20:66. doi: 10.3390/ijms2001 0066

68. Morgan AR, Touchard S, Leckey C, O'Hagan C, Nevado-Holgado AJ, Barkhof F, et al. Inflammatory biomarkers in Alzheimer's disease plasma. Alzheimers Dement. (2019) 15:776-87. doi: 10.1016/j.jalz.2019.03.007
Conflict of Interest: The authors declare that the research was conducted in the absence of any commercial or financial relationships that could be construed as a potential conflict of interest.

Copyright (c) 2019 Isacson, Brekk and Hallett. This is an open-access article distributed under the terms of the Creative Commons Attribution License (CC BY). The use, distribution or reproduction in other forums is permitted, provided the original author(s) and the copyright owner(s) are credited and that the original publication in this journal is cited, in accordance with accepted academic practice. No use, distribution or reproduction is permitted which does not comply with these terms. 